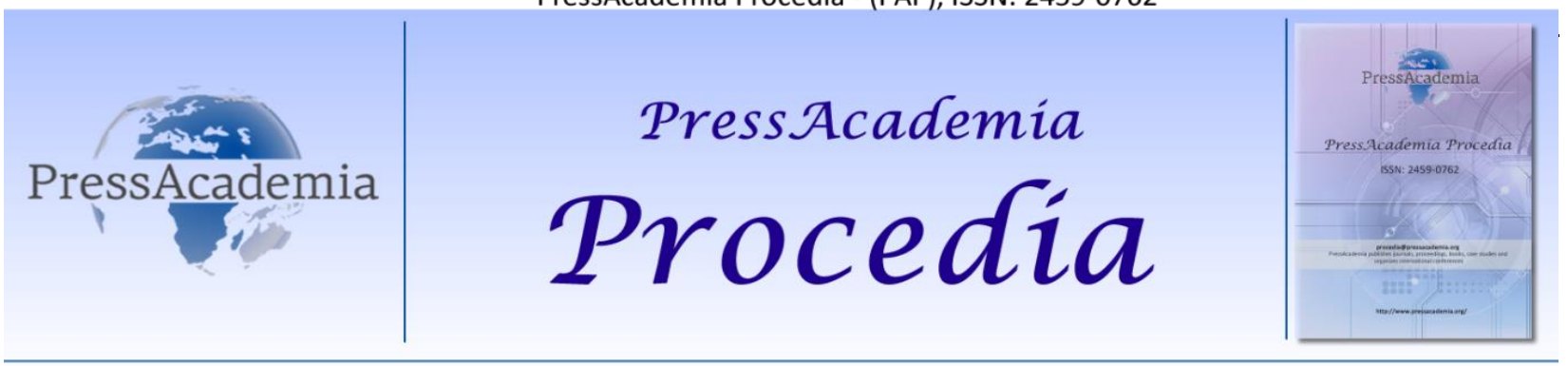

2nd World Conference on Technology, Innovation and Entrepreneurship

May 12-14, 2017, Istanbul, Turkey. Edited by Sefer Şener

\title{
APPLICATION OF GEOGRAPHICAL INFORMATION SYSTEM (GIS) FOR SPATIAL DISTRIBUTION OF ELECTRICAL TRANSFORMERS IN IKORODU DISTRICT, LAGOS STATE, NIGERIA
}

\author{
DOI: 10.17261/Pressacademia.2017.613 \\ PAP-WCTIE-V.5-2017(51)-p.371-378
}

\author{
Akinwumi A. Akinpelu ${ }^{1}$, Olufemi F. Iyiola ${ }^{2}$ and Abiodun O. Abisuga ${ }^{3}$ \\ ${ }^{1 \& 3}$ Department of Building Technology, Lagos State Polytechnic, Lagos, Nigeria. aaakinpelu@yahoo.com, felixiyiola@yahoo.com \\ ${ }^{2}$ Department of Surveying \& Geoinformatics, Federal School of Surveying, Oyo, Nigeria. abisuga_olatunji@yahoo.com
}

\begin{abstract}
Epileptic power supply is a major problem which has great impact on socioeconomic development of Nigeria. Power Holding Company of Nigeria (PHCN) is responsible for power distribution in the country and one of the major challenges is the haphazard distribution of their facilities, most especially, electrical transformers. In addition, spatial locations of electrical transformers and other attribute data are kept using manual approach and in some cases, the records are not available. This study is aimed at using Geographic Information System (GIS) to take inventory of PHCN electrical transformers in Ikorodu district of Lagos, in order to assess their spatial distribution. The research method adopted includes converting the existing map of the study area into digital format through scanning and digitizing, collection of spatial locations of electrical transformers' with GPS receivers and attribute data through social survey. ArcGIS software was employed to create spatial database for forty two (42) electrical transformers located in the study area and various spatial analyses such as query, overlay, buffering, etc. were performed to view the spatial distribution of PHCN facilities. The spatial database created can be easily updated from time to time at a fast rate and reduced cost, and without passing through the whole process of map production. Appropriate recommendations were made for socioeconomic development of the country and effective management of the PHCN facilities. The outcome of the study can be adopted in other developing countries with similar challenges.
\end{abstract}

Keywords: Geographic information system (GIS), global positioning system (GPS), spatial location, transformers.

\section{INTRODUCTION}

\subsection{Background to Electricity Network in the Last Few Decades}

Electric power industries have been developing transmission systems to follow up with the rapid growth of the power demand. On the other hand, the distribution of transformers has been getting restricted, because of development of rural areas and the growing concern over environmental issues. Generally, Electric network can be described as a set of devices used to transport electric power from the power plants to the consumers.These various devices include Overhead transmission lines, underground cables (found mostly in developed countries), switching equipments (circuit breakers and disconnectors), substations (i.e. subsystems equipped with transformers that allow power transfer between systems operating at different voltage levels) and reactive power compensation devices (such as capacitors and reactors).GIS can effectively be used to manage and monitor information on the distribution of transformers to end-users including information describing their spatial and non-spatial attributes such as geographical location and electricity use.

Ikorodu Division is one of the five divisions in Lagos state. With an area approximately 161, 954 square kilometers. It is the second largest local government in Lagos State. It lies about 36 kilometers north-east of the city of Lagos and 26 kilometers from Ikeja, the State capital. It is geographically located on latitudes $3^{0} 26^{\prime} 31.82^{\prime \prime} \mathrm{E}$ and $3^{0} 43^{\prime} 5.13^{\prime \prime} \mathrm{E}$ and longitude $6^{0} 41^{\prime} 51.13 \mathrm{~N}$ and $6^{\circ} 31^{\prime} 20.95^{\prime \prime} \mathrm{N}$. Like most parts of Lagos State, Ikorodu Local Government Area is a veritable lowland region with relatively 
flat undulating features, stretching about 18 kilometers from east to the west, along the Lagos lagoon front. With the opening of Lagos-Ikorodu highway in 1953, Ikorodu division has been an important gateway to Nigeria Hinterland. The climate of Ikorodu Division is similar to that of the entire country, Nigeria, which lies in the world's tropical region. There are two separate seasons, the rainy season which runs from April to October and dry season from November to March. Ikorodu is in the rain forest belt with common vegetation in Nigeria's southern part interspersed with plenty of cassava, yam, and cocoa, kolanut and maize plantations, because of the sandy nature of the soil. The inhabitants of Ikorodu Division are ljebus, a Yoruba sub- group. The dialect of the people is ljebu, a Yoruba dialect. Today, the general Yoruba language (or Lagos dialect) is common, particularly among the youths. Farming, hunting and fishing have been the chief occupations of the people. Food crops which are popular in the area are vegetable, melon and beans etc. Cocoa and kolanut are no longer extensively grown as in the past. There are over 200 notable towns and villages in Ikorodu Local Government Area. The six major towns are Ikorodu (headquarter of the Local Government), Imota, Igbogbo, Ipakodo, Ijede and Ibeshe. Other notable towns include Baiyeku, Isiu, Agura, Igberigbe, Oyin, Oreta, Igbokuta, Mowo, Odo- nla (surrounded by Ikorodu Industrial Estate), Odongunyan and Maya.

\subsection{Aim and Objectives of the Study}

The aim of the study is to generate a geospatial model for electricity and facilities to provide a better understanding towards effective distribution and conservation of electricity. The objectives of the study are:

1. To carry out an appraisal of the existing transformer distribution network in the study area;

2. To map the existing transformers' distribution facilities in the study area;

3. To estimate the number of existing transformers in the study area; and

4. To conduct gap analysis of transformer requirements in the study area.

\section{METHODOLOGY}

The methodology adopted for this study are database design and creation. Entities were identified and database created upon which queries and spatial analyses were conducted.

\subsection{Data Acquisition}

The Data acquisition began with the physical phenomenon to be measured. The first step in the methodology of this work was the design of a geodatabase for the entities of interest in the study area. The entities include the Low Tension Electric Poles, High Tension Electric Poles; high and low tension cables, Distribution substation transformer, power transformers, feeders and Injection Substation. This was closely followed by the collection of the required data from the study area. In this case, there were two types of GIS data involved which included: spatial and Attribute data.

\subsection{Spatial Data}

The spatial data used for the research study include the following;

(i) Base Map: The base map consists of roads, buildings and facilities digitized from a High-Resolution Image data

(ii) GPS Data: GPS Collection points on the available PHCN (Power Holding Company Nigeria) facilities (Poles, Transformers, etc) were acquired from the field of study using a Hand Held GPS.

\subsection{Attribute Data}

The Attribute data includes the following information which was acquired from the PHCN (Power Holding Company Nigeria), Ikorodu District Office and consumers;

(i) Consumer Details: Meter Account Number, Address of the consumer, the Line Transmission Pole/Pillar to which a consumer is connected;

(ii) Electrical Network Details: $11 \mathrm{kV}$ line diagrams with cable sizes, lengths, distribution substation (DSS) transformers, parameters of the equipments, pillars, poles and low voltage networks

(iii) Transformer Details: The details about transformers and other related facilities for this study, PHCN (Power Holding Company Nigeria) bills were acquired so as to acquire information on the average amount of energy consumption. 


\subsection{Database Design, Creation, Processing and Analysis}

Database design is the process of producing a detailed data model of a database. This data model contains all the needed logical and physical design choices and physical storage parameters needed to generate a design in a Data Definition Language, which can then be used to create a database. A fully attributed data model contains detailed attributes for each entity.

The database in the course of this study supports an object oriented vector data model. In this model, real world entities were represented as objects with their various properties, behavior and relationships. In GIS, a database is often referred to as a spatial database or geodatabase and it is the heart of GIS. This process involved the analysis and modeling of real world entities and their interrelationships in such a way that maximum benefits were derived while utilizing minimum amount of data, Kufoniyi, (1998).

Data were formally entered into their respective tables, created in ArcCatalog, in the Arc Map environment. After the data entry process, the personal geodatabase was saved in ArcMap in a folder for easy recovery, geospatial analyses and queries carried out on them. The data stored in the database forms the information base. Once the layers were digitized, the nonspatial data were then added as attributes to the digitized features. This attribute table was linked to the spatial themes containing geographic information. The database created included location and descriptive information for all the different components of the system.

To estimate the areas in the study area that were of short comings in terms of the distribution and develop an estimation trend in the consumption of electricity, the following were operations carried out during the course of this study; overlay operations, spatial queries, proximity analysis and measurement of electricity consumption trend pattern.

\section{RESEARCH FINDINGS}

\subsection{Nature of Transformer Distribution Network in the Study Area}

Figure 1 below shows the map of electricity distribution network in the area of study. The map displays the geographic location of all the facilities in the selected area of interest. The entities identified included the Low Tension Electric Poles, High Tension Electric Poles; high and low tension cables, Distribution substation transformer, power transformers, feeders and Injection Substation.

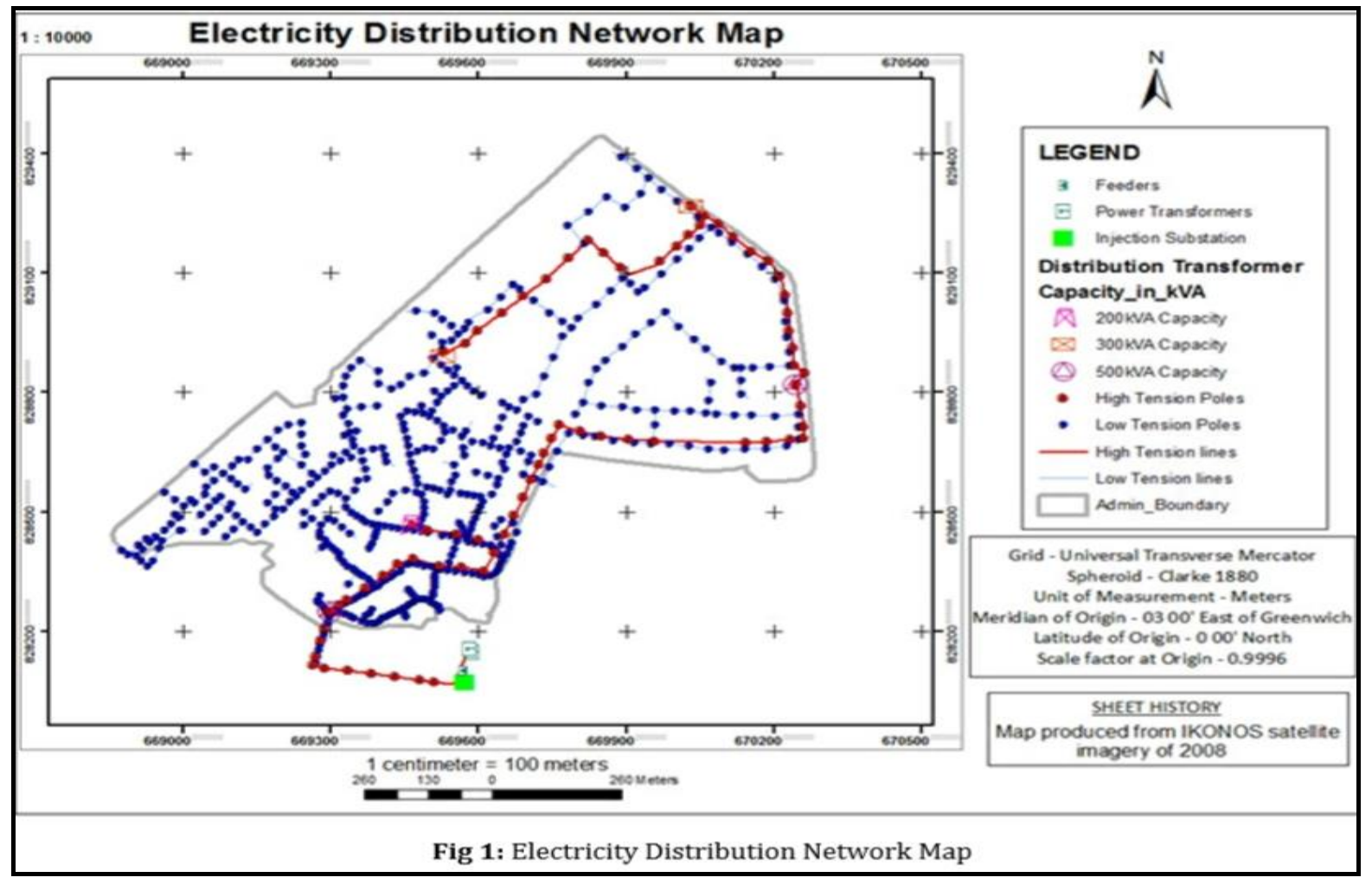


Figure 2 shows a more detailed map of the electricity distribution facilities connected to the end users - consumers.

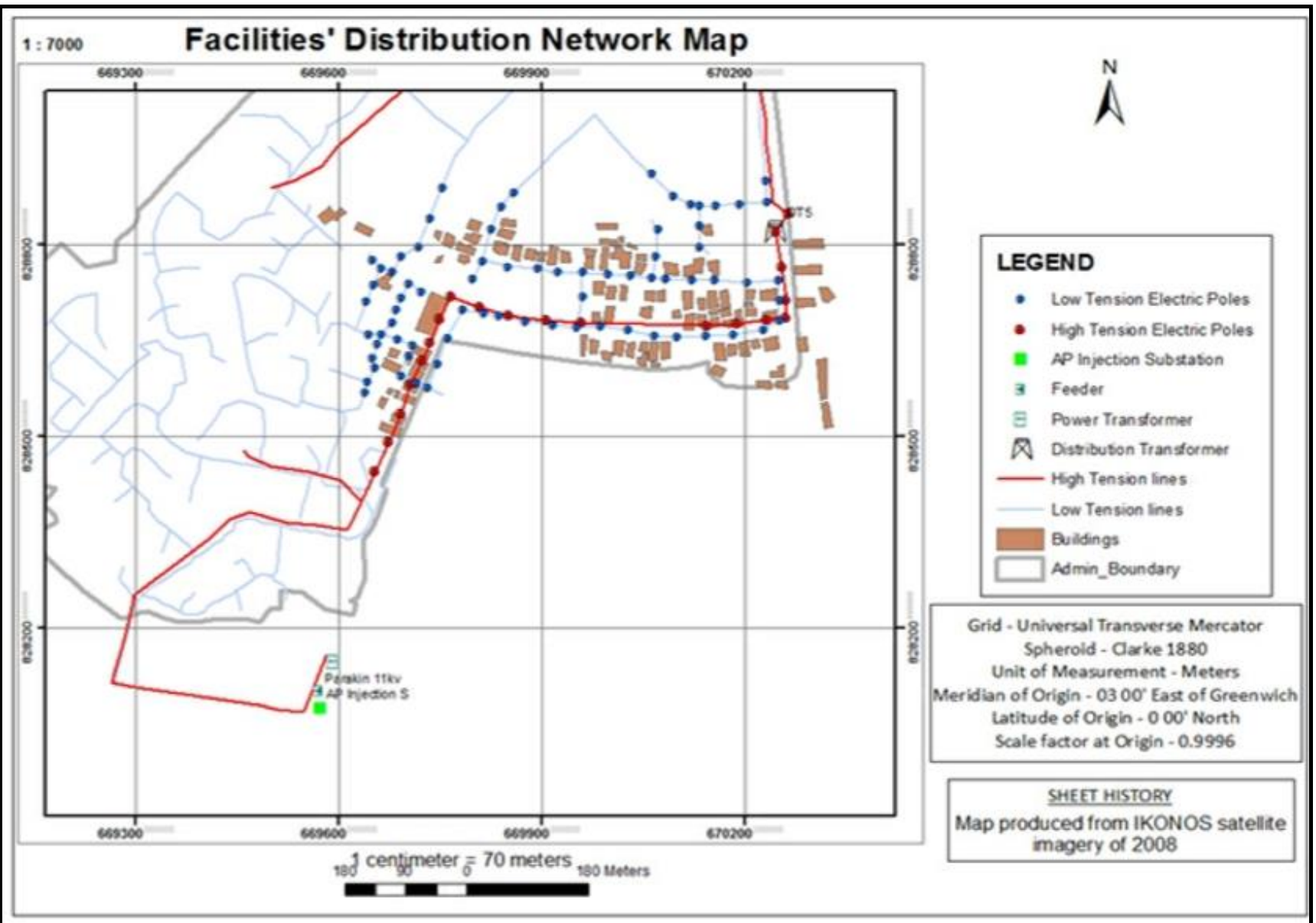

Fig. 2: Map showing the facilities involved in the distribution of electricity to consumers

Information showing all the facilities involved in the service of electricity to the consumers in a selected part of the area of interest is shown in Figure 2 above provides a better understanding of the electricity distribution network pattern.

\subsection{Spatial Queries Generation}

In GIS, a spatial operation tool is essential for processing or manipulating of data to suit user's need. Geographical Information Systems have a distinctive disparity from other Information Systems which is in the area of spatial analyses. In this project, the spatial search operation was carried out through query generation to retrieve the information stored in the database pertaining to certain systematically defined attributes within the database to answer spatially related questions. This operation involved the link between the database and the map of the selected area of interest. Spatial queries were generated to provide answers to the application use of GIS in developing a model (representation of reality) for the PHCN facilities.

Database query can be referred to as the selection of various combinations of various tables for examination; it involves the retrieval of information stored in the database using Structured Query Language (SQL). However, the queries generated are basically through database extraction in ArcMap 10.2. Some other queries can also be generated based on the user's need. In the course of the project, the results obtained have assisted in the several areas;

i. Monitoring the status of the facilities in the Feeder so as to know the status of the facilities.

ii. Retrieval of Geographical Information of the facilities (Transformer). The spatial information would include coordinates ( $\mathrm{X}$ and $\mathrm{Y})$, and symbol representation, capacity and location. 
iii. Prioritization of facility (Transformer) replacement based on the available information. In this study, of all the existing facilities on ground, none was due for immediate replacement.

iv. Update the information system in the case whereby new facilities (Transformer) are to be installed. In the near future, when new buildings are connected to the existing facilities, the information system can be updated.

Figure 3 suggests proposed location for the installments of new Distribution Substation Transformers within the study area. This was generated based on the average consumption rate by the existing households and the amount of Power generated by each distribution substation transformers connected to them.

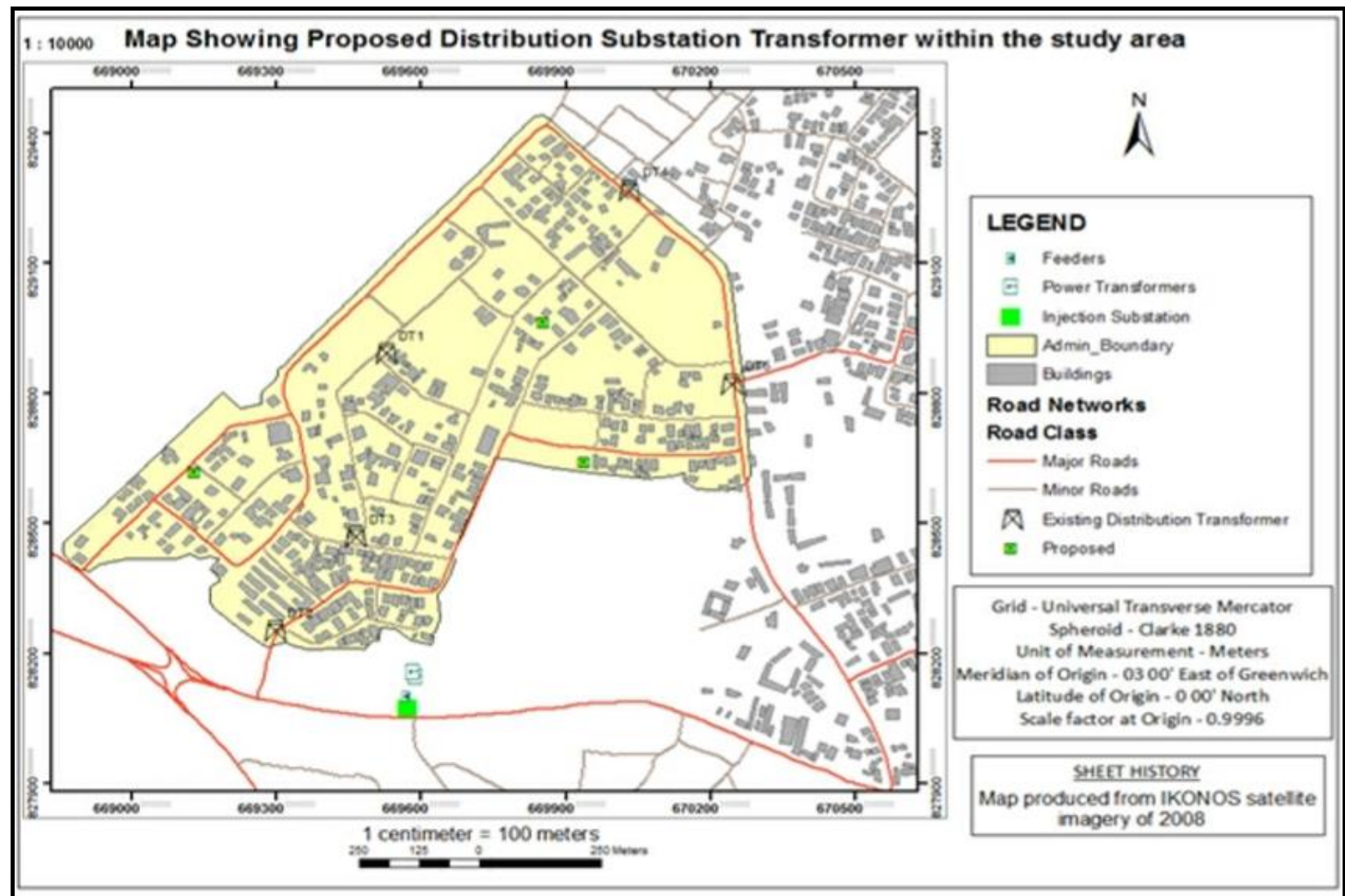

Fig 3: Map showing existing and proposed location of DSS

The above results are expected to equally provide good information for other professionals, which may include Urban Planners, Construction Managers, Engineers, etc. the knowledge of the locations (spatial locations) of the facilities will help to avoid or reduce damages done to these facilities during construction works especially in newly developed areas (such as, Parakin). Proximity Analysis and Estimation of Consumption Trends Other analyses were carried out during the course of this work. Proximity Analysis such as Buffering analysis was carried out to identify the areas for the requested availability and quality of energy supply. As shown in Figure 4 below, the buildings connected to a particular transformer (DT5 in this case) that fall outside a $300 \mathrm{~m}$ radius experience a drop in voltage compared to those within the buffered area. The buffering analysis performed helped in identifying the pattern of the supply and distribution of power in terms of voltage within the study area. 


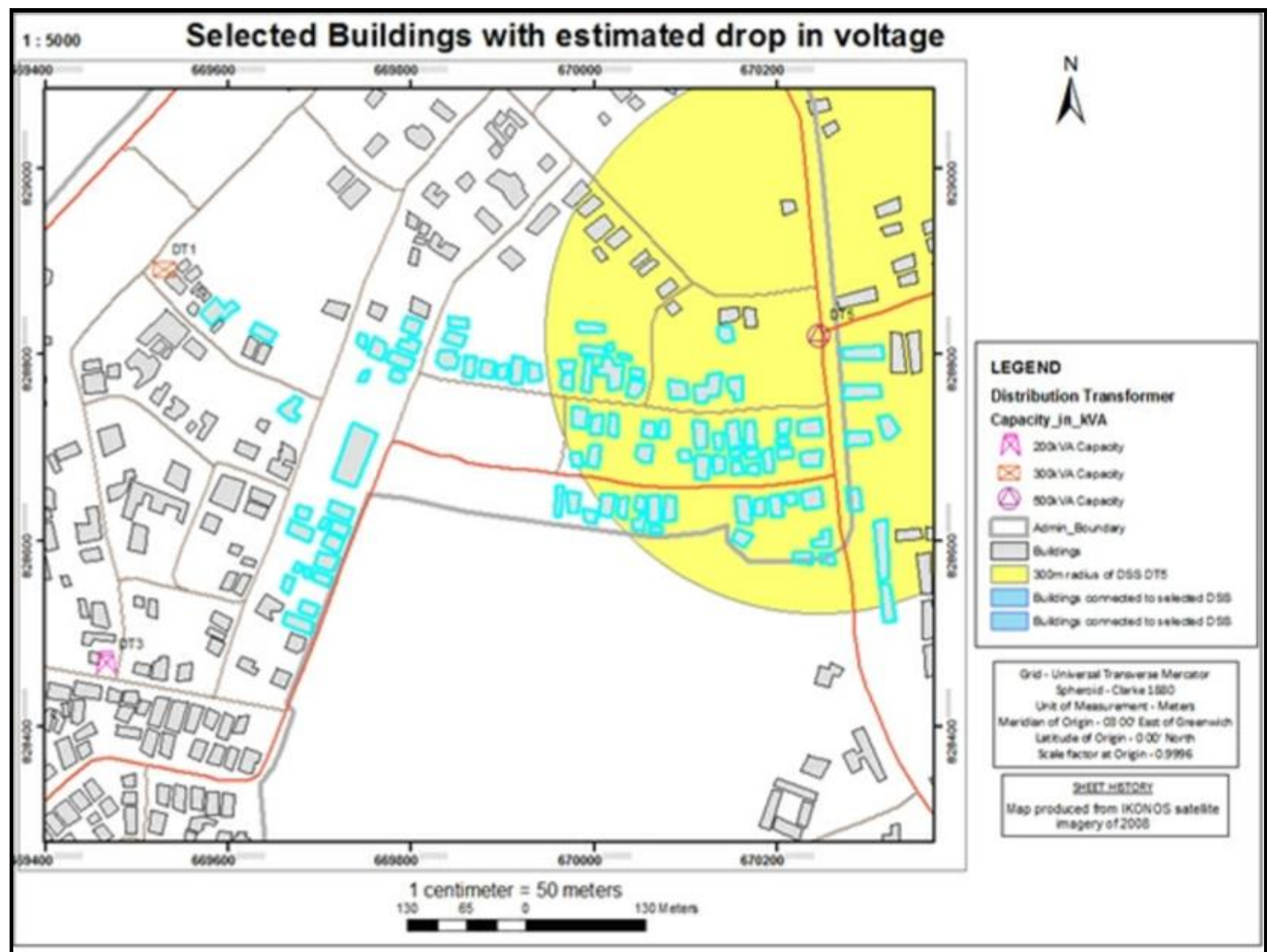

Fig 4: Selected Buildings with estimated drop in voltage

In the case of Figure 5, the result displayed was based on the average consumption rate of the households within the study area. Based on the level of consumption, it clearly shows that most of the households within the area of interest were classed as residential dwellings. The results displayed show the variation in the energy consumption rate within the area. This is because of the various types of electrical appliances used by different households within the area. As represented in the map displayed, the Buildings with darker colors consume higher consumption rate than those with brighter colors. 


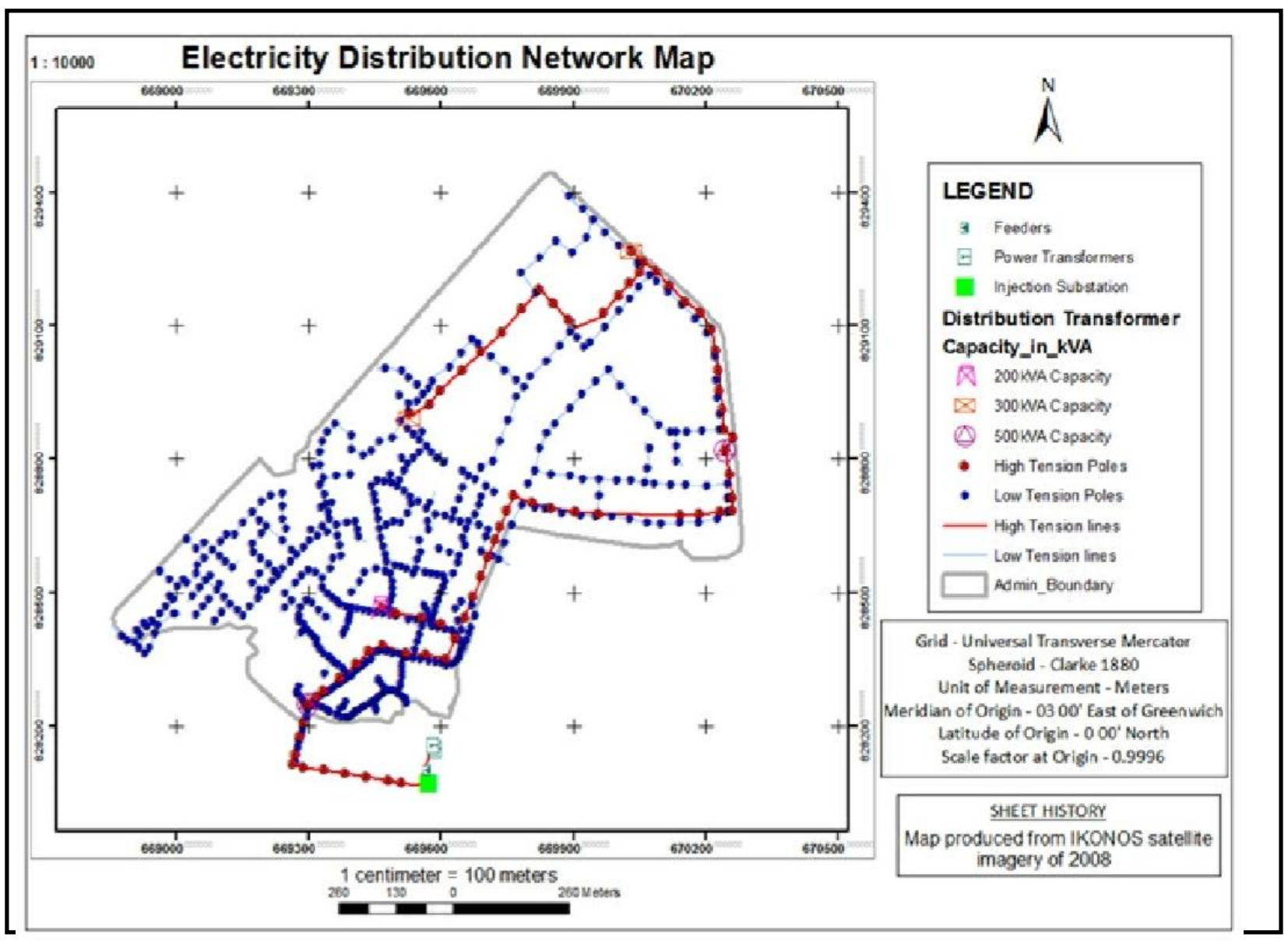

Figure 5: consumption rate of the households within the study area

In order to estimate the consumption trend during the course of this work, other analyses were performed. The relevance and importance of mapping utilities in GIS environment is to provide spatial solutions in a real time manner. The common problems that have been identified in the Power Utility Sector include the following;

1. Unequal distribution/transmission of load;

2. Bad conditions of the equipments due to improper monitoring and maintenance;

3. Frequent power surge due to natural incidences It was been observed that in the study area electrical facilities are either obsolete or too old for efficient performance.

Therefore, routine maintenance and replacement are necessary for efficient performance the electrical equipment in the study area. The threshold of each electrical facility should however be noted at installation and strictly adhered to during operational period. In advanced GIS, locating the facility and finding the exact fault wherein it has occurred could be substantiated by hand held palmtops. The notified location on the spatial network wherein the fault has occurred could be easily identified and trained engineers could be alerted to go to the exact area and rectify the problem immediately. This showed that the major advantage of GIS in Electricity distribution network is the location component.

The electricity distribution network map of the study area revealed the spatial distribution and locations of the electrical facilities within $11 \mathrm{kV}$ feeder in the area of interest. In the course of this work, it was observed that electricity consumers within a 300meter radius to a distribution substation transformer, experience higher voltage of power compared to the households outside the radius. It was however noted that about $55 \%-60 \%$ of households connected to the distribution substation transformers experience average voltage of power supply while about $40 \%-45 \%$ experience drop in voltage of power supply. 
The gap analysis showed that, voltage drop in power supply is experienced the farther the households are connected to a distribution transformer.

As shown in figure 5, the system shows descriptive information about the households and their average rate of consumption. This clearly reveals the consumption rate pattern within the households connected to all the facilities within the area. Within the network, $37 \%$ of households consume high amount of electricity, $36 \%$ consume average and $27 \%$ consume less amount of electricity.

The spatial analysis and the resulting maps provided a better knowledge and understanding on spatial relationships among electricity facilities and consumer demands. Such knowledge is expected to help them know the sections of the service area that lack inadequate services. It is also expected to serve as a guide to them in order to know where they could extend or improve their services and areas that need new installation based on the distribution of power.

\section{CONCLUSION AND RECOMMENDATIONS}

The study clearly indicates the capability of spatially enabled information system in the management of electricity distribution network. Spatial and attribute data of power distribution network of any part of the selected areas of interest of this study, which are presently acquired, processed, managed, stored and presented in analogue form, can be digitalized. Ayeni et al., (2003) noted that Geospatial Information (GI) is very essential to economic planning and national development. This is buttressed further by Alamu and Ejiobih (2002), when they concluded that a well maintained utility information infrastructure gives up-to-date information on what is where, the state of it, the reaction other actions on it would cause, how it can be harnessed for optimum use of the people and economy. It has been shown that GIS has been employed as one of the technologies for better and improved delivery of networked services. This further enlightens that regardless of cost, GIS has prominently improved the manner of service delivery with respect to time period.

Conclusively, it has been observed that GIS applications have not reached the optimum exploration and there is still room for further exploration and extension in the field as far as utility service delivery like in the case of electricity distribution is concerned. The following recommendations are advanced for efficient electricity distribution networks;

1. More efforts must be made to bring in refined and scientific approaches such as Geographic Information Systems into the management of electricity distribution network.

2. Training programs should be organized for technical online staff of electricity distribution on the integration of GIS in the management/monitoring of electricity distribution.

3. The user requirement and survey analysis conducted before implementation of electricity projects should include spatial information system from the onset so as to forestall drop in voltage within the distribution network.

4. Establishment of more distribution substation transformers in low voltage area within the study area.

\section{REFERENCES}

Alamu, E. O. and Ejiobih, H. C. (2002). Utility Information Infrastructure Needs in Utility Organisations in Nigeria: A Case Study of Niger State Water Board. Proceedings of the Technical Session of the 37th Annual General Conference and Meeting of Nigerian Institution of Surveyors, Owerri, Imo State, Nigeria, pp. 85-88.

Ayeni, O. O., Kufoniyi, O. and Akinyede, J. O. (2003). Towards a National Geospatial Information Policy for Nigeria", Proceeding of the Technical Session of the 38th Annual General Conference and Meeting of Nigeria Institution of Surveyors, Lokoja, Kogi State, Nigeria, pp. 21.

Douglas, D. H., (1994), Least Cost Path in GIS Using an Accumulated Cost Surface and Slope Lines. Cartographica 31 (3): 37-51.

Emengini, E. J. (2004). Application of Geographic Information System (GIS) to Utility Information Management: A Case Study of Onitsha-North L.G.A., Anambra State, Nigeria. Unpublished M.Sc. Thesis Submitted to the Department of Surveying and Geoinformatics, Nnamdi Azikiwe University, Awka, Anambra State, Nigeria.

Ezeigbo, C. U. (1998). Application of Geographic Information Systems (GIS) to Utility Mapping, in C. U. Ezeigbo (ed.), Principles and Applications of Geographic Information Systems, Lagos, Panef Press, pp. 124-131.

Korte, G (2001). The GIS book: how to implement, manage and assess the value of Geography

Kufoniyi, O. (1998). Database Design and Creation in C. U. Ezeigbo (ed.). Principles and Applications of Geographic Information Systems, Lagos, Panaf Press, pp. 1-15.

Sipes, J. L. (2007). Spatial Tech- GIS for the utilities Industry. Cadalyst Publications - www.usgs.com - www.gis.rgs.org 